\title{
Adalimumab successful in sarcoidosis patients with refractory chronic non-infectious uveitis
}

\author{
R. J. Erckens • R. L. M. Mostard • P. A. H. M. Wijnen • \\ J. S. Schouten • M. Drent
}

Received: 2 June 2011 /Revised: 26 September 2011 / Accepted: 3 October 2011 /Published online: 27 November 2011

(C) The Author(s) 2011. This article is published with open access at Springerlink.com

\begin{abstract}
Introduction Adalimumab, a humanized monoclonal antibody targeted against TNF- $\alpha$, has proved to be successful in the treatment of uveitis. Another anti-TNF- $\alpha$ agent, i.e., infliximab, has been reported of benefit in the treatment of refractory sarcoidosis. The aim of this prospective case series was to evaluate the effect of adalimumab on intraocular inflammatory signs and other relevant clinical manifestations (lung function, serological inflammatory parameters, and fatigue) of sarcoidosis.

Methods Sarcoidosis patients with refractory posterior uveitis ( $n=26,17$ females, 41 eyes in total) were system-
\end{abstract}

R.J. Erckens and R.L.M. Mostard contributed equally to this work.

R. J. Erckens $(\bowtie) \cdot$ J. S. Schouten

Department of Ophthalmology,

Maastricht University Medical Centre,

P. Debyelaan 25,

6229 HX Maastricht, The Netherlands

e-mail: r.erckens@mumc.nl

R. J. Erckens · R. L. M. Mostard - P. A. H. M. Wijnen •

J. S. Schouten $\cdot$ M. Drent

ild care team, Maastricht University Medical Centre,

Maastricht, The Netherlands

R. L. M. Mostard

Department of Respiratory Medicine, Atrium Medical Centre,

Heerlen, The Netherlands

P. A. H. M. Wijnen

Department of Clinical Chemistry,

Maastricht University Medical Centre,

Maastricht, The Netherlands

\section{Drent}

Department of Respiratory Medicine,

Maastricht University Medical Centre,

Maastricht, The Netherlands atically followed for 12 months after initiation of adalimumab $40 \mathrm{mg} s c$ once a week. Inclusion criteria were nonresponsiveness to prednisone and methotrexate (MTX) or intolerance to these drugs. Adjunctive therapy with prednisone and MTX was tapered during treatment with adalimumab. Localization and improvement, stabilization or deterioration of intraocular inflammatory signs was scored. Pulmonary function- and laboratory testing were performed and Fatigue Assessment Scale was completed. Results at baseline, 6 months, and 12 months were compared.

Results Choroidal involvement resolved in 10/15 patients, five had partial improvement; vasculitis resolved in $1 / 1$ patient; papillitis resolved in $7 / 8$ patients, one had partial response; macular edema resolved in $5 / 8$ patients, three had partial response; vitreous cleared completely in $5 / 5$ patients. Overall outcome regarding intraocular inflammatory signs showed improvement in 22 patients (85\%) and stabilization in four patients $(15 \%)$. At 12 months, no recurrences were reported in those successfully treated. Laboratory parameters of inflammatory activity (C-reactive protein; serum angiotensin-converting enzyme and soluble interleukin-2 Receptor) improved $(p<0.01)$. Moreover, fatigue improved in $14 / 21(67 \%)$ of the patients suffering from fatigue and the diffusion capacity for carbon monoxide (DLCO) improved in $7 / 8(88 \%)$ of patients with a decreased DLCO $(p<0.01)$. The dosage of both prednisone and MTX could be tapered down significantly $(p<0.01$ and $p<0.05$, respectively).

Conclusions Adalimumab appeared successful in sarcoidosis patients with refractory chronic non-infectious uveitis showing improvement in intraocular inflammatory signs as well as in other relevant clinical indicators of disease activity. Future randomized studies are needed to determine the optimal dosage, dose interval and duration of therapy in refractory multisystemic sarcoidosis. 
Keywords Adalimumab - Anti-TNF-alpha treatment . Sarcoidosis · Uveitis

\section{Introduction}

Uveitis is a sight-threatening eye disease inflicted by autoimmune disorders or infectious agents [1]. Sarcoidosis is a multisystemic granulomatous chronic disorder with unknown etiology $[2,3]$. In the eye this can cause uveitis with anterior chamber cells and flare, corneal deposits, synechiae formation, macular edema, vasculitis, retinitis, papillitis and/or a vitritis [4]. Ocular manifestations of systemic sarcoidosis have significant impact on visual prognosis $[5$, 6]. Sarcoidosis patients with chronic disease often require prolonged treatment. Moreover, since sarcoidosis is a systemic disease, the effect of treatment on the various affected organs is important in deciding which therapy is the most appropriate. Regarding eye involvement, intermediate uveitis, posterior uveitis and panuveitis all require aggressive treatment regimen with immunosuppressive drugs in order to preserve vision and function of the eye $[6,7]$. Corticosteroids remain the mainstay of treatment. However, in case this treatment does not have a favorable outcome or if disabling side-effects, which accompany prolonged treatment occur, use of other alternative, steroidsparing agents is mandatory. Methotrexate has been proven to be a good alternative [8]. In case this therapy also fails, use of biologic agents which block tumor necrosis factoralpha $(\mathrm{TNF}-\alpha)$ can provide effective treatment for the diverse manifestations of sarcoidosis [9-11]. Among the TNF- $\alpha$ inhibitors, infliximab has been studied most extensively in sarcoidosis $[9,11-13]$. Anti-TNF- $\alpha$ treatment has been efficacious for the treatment of refractory ocular inflammatory disease [7, 14-18].

Adalimumab, a humanized monoclonal antibody targeted against TNF- $\alpha$, has also been reported useful in treating uveitis, sarcoidosis and various other auto-immune disorders $[9,18-26]$. The aim of this prospective case series was to evaluate the effect of adalimumab on intraocular inflammatory signs and other relevant clinical manifestations (lung function, laboratory inflammatory parameters, and fatigue) in sarcoidosis patients with refractory chronic non-infectious uveitis.

\section{Materials and methods}

All sarcoidosis patients referred to the sarcoidosis management team of the Maastricht University Medical Centre (MUMC), the Netherlands (a tertiary referral center), who started treatment with the anti-TNF- $\alpha$ drug adalimumab initiated by our ophthalmologist (RE) because of refractory posterior uveitis between March 2006 and December 2009 were followed systematically according to a clinical protocol for 12 months. Adalimumab was started based on the following clinical criteria: patients with refractory posterior uveitis who did not respond to the original therapy with immunosuppressive drugs (both prednisone and methotrexate; $n=20$ ) and patients who responded to previous therapy with these immunosuppressive drugs, but demonstrated severe adverse effects $(n=6)$. It has to be emphasized that in order to prescribe the drug in the Netherlands for the treatment of uveitis, the patient had to be treated with at least two different immunosuppressive drugs, previously. Therefore, it is not allowed to use this drug as first choice in treating severe uveitis. Adalimumab was administrated at a dose of $40 \mathrm{mg}$ subcutaneously once a week. Patients were instructed to inject themselves and to report side effects immediately. Only patients who were treated with adalimumab for at least six months and completed the follow-up period of 12 months were included in the analysis $(n=26)$.

The diagnosis sarcoidosis was based on consistent clinical features and bronchoalveolar lavage fluid analysis, in accordance with the WASOG guidelines with biopsyproven noncaseating epithelioid cell granulomas confirming sarcoidosis in 21/26 (77\%) patients [27]. None of these patients had a relevant medical history or co-morbidity. At initial diagnosis, the presence of active tuberculosis was excluded. Just before initiating anti-TNF-alpha treatment a Quantiferon ${ }^{\circledR}$ - TB Gold in combination with the tuberculin skin test was repeated to exclude latent tuberculosis infection (LTBI) as this is a contraindication for treatment with TNF- $\alpha$ inhibitor therapy and also recommended in the guidelines of our hospital $[4,28]$. At both time points, these tests were negative in all included patients.

\section{Evaluation of clinical course}

The different outcome measures were scored at baseline, 6 months and 12 months.

Evaluation of uveitis

All the patients were evaluated by the same ophthalmologist (RE). He screened the patients for the presence of uveitis on the following items. Using slit-lamp examination the eye was scrutinized on the presence of noduli in the conjunctival tissue; corneal deposits; anterior chamber cells and flare; anterior and posterior synechiae formation. These findings are not included because in our cases the anterior segment had no active signs of inflammation. In fact, 21 patients had no signs at all of uveitis anterior, while five patients had uveitis anterior in the past that showed no activity at the initial examination. Using funduscopy, the 
presence of macular edema, snowballs or vitreous opacities; multiple chorioretinal peripheral lesions; nodular and/or segmental periphlebitis and/or macroaneurysms or optic disc nodules were recorded. The Standardization of Uveitis Nomenclature (SUN) for clinical data was used in conjunction with the results of the first international workshop on the International Criteria for the Diagnosis of Ocular Sarcoidosis (IWOS) to score the location and activity of the uveitis $[4,29]$.

Additionally, fluorescein angiography (FA, Topcon, TRC-50 EX) or optical coherence tomography (OCT, Zeiss, Stratus model 3000) was performed in 20 patients to detect the presence of vasculitis, papillitis, or macular edema. In 16 cases, these findings were present bilateral. In total, three patients refused FA; in the remaining three cases it was thought that FA would have no beneficial effect.

The outcome of the specific inflammatory signs was scored as resolved if complete clearance of the specific inflammatory activity was seen; partial response if the specific inflammatory activity had decreased; stabilization if the specific inflammatory activity remained unchanged and deterioration if the specific inflammatory activity had increased.

Overall outcome of intraocular inflammatory signs was scored as improvement if at least one of the scored inflammatory signs showed a complete clearance in the absence of deterioration of other inflammatory signs; partial improvement if at least one of the scored inflammatory signs improved in the absence of deterioration of other inflammatory signs; stabilization if all inflammatory signs remained unchanged; deterioration if at least one of the inflammatory signs increased.

Pulmonary evaluation

Chest X-rays (CXR) were graded by one single person, blinded to the clinical data and according to the standard radiographic staging for sarcoidosis. According to the Scadding radiographic staging system, five stages of radiographical abnormality (0-IV) were recognized [27]. The CXR stages of the included patients at the start of treatment with adalimumab were, respectively: 16 patients $(62 \%)$ stage 0 , four patients stage I (15\%), four patients stage II $(15 \%)$, and two patients $(8 \%)$ stage III.

Lung function measurements, including forced vital capacity (FVC) were measured with a pneumotachograph (Masterlab, Jaeger, Würzburg, Germany). The diffusing capacity for carbon monoxide (DLCO) was measured by the single-breath method (Masterlab, Jaeger, Würzburg, Germany). Values were expressed as a percentage of predicted values. Lung function characteristics of the included patients are shown in Table 1 .

\section{Laboratory assays}

The C-reactive protein (CRP) concentration and serum levels of angiotensin converting enzyme (ACE) and soluble interleukin-2 receptor (sIL-2R) were measured as described in a previous study of our group [30].

\section{Fatigue questionnaire}

The Fatigue Assessment Scale (FAS) is a ten-item questionnaire to asses fatigue. Five questions reflecting physical fatigue and five questions assessing mental fatigue [31].

The response scale is a five-point scale ( 1 never to 5 always); scores on the FAS can range from 10 to 50 . The cutoff score of the FAS was 22. A score below 22 indicates no fatigue, whereas a score of 22 or higher indicates fatigue.

Statistical procedure

Differences between results at baseline, 6 months and 12 months were tested for statistical significance using the

Table 1 Summary of relevant clinical characteristics of the studied sarcoidosis patients and the effect on clinical manifestations after 6 and 12 months of treatment with adalimumab

\begin{tabular}{|c|c|c|c|}
\hline & $\begin{array}{l}\text { Total population; } \\
n=26 \text {; baseline }\end{array}$ & $\begin{array}{l}\text { After } 6 \text { months treatment } \\
\text { with adalimumab }\end{array}$ & $\begin{array}{l}\text { After } 1 \text { year treatment } \\
\text { with adalimumab }(n=25)\end{array}$ \\
\hline DLCO $(\%$ predicted \pm SD) $($ normal $>80 \%$ of predicted $)$ & $88 \pm 18$ & $92 \pm 12$ & $90 \pm 15$ \\
\hline FVC $(\%$ predicted \pm SD $)($ normal $>80 \%$ of predicted $)$ & $97 \pm 15$ & $94 \pm 22$ & $102 \pm 20$ \\
\hline $\mathrm{CRP}($ mean $\pm \mathrm{SD})\left(2-9 \mu \mathrm{g} \cdot \mathrm{ml}^{-1}\right)$ & $4.8 \pm 5.3$ & $2.4 \pm 2.6^{*}$ & $3.6 \pm 4.4^{*}$ \\
\hline $\mathrm{ACE}(\operatorname{mean} \pm \mathrm{SD})\left(9-25 \mathrm{U} \cdot \mathrm{L}^{-1}\right)$ & $19 \pm 8$ & $14 \pm 9 *$ & $15 \pm 10$ \\
\hline $\mathrm{sIL}-2 \mathrm{R}(\mathrm{mean} \pm \mathrm{SD})\left(240-3154 \mathrm{pg} \cdot \mathrm{ml}^{-1}\right)$ & $2803 \pm 2224$ & $1888 \pm 1537 *$ & $2188 \pm 1801 *$ \\
\hline FAS $($ mean \pm SD) $(<22:$ no fatigue $)$ & $31.1 \pm 11.1$ & $28.5 \pm 7.8^{*}$ & $28.9 \pm 10.0^{*}$ \\
\hline
\end{tabular}

$n$ : number; $S D$ standard deviation; $D L C O$ diffusion capacity for carbon monoxide; $F V C$ forced vital capacity; $C R P C$-reactive protein; $A C E$ serum angiotensin-converting enzyme; $s I L-2 R$ soluble interleukin-2 Receptor; FAS Fatigue Assessment Scale

${ }^{*} p<0.01$ compared with baseline 
paired t test in case of continuous variables or Chi-square test in case of categorical variables. Statistical analyses were performed using SPSS, version 15.0 for Windows (SPSS Inc., Chicago, IL, USA). A $p$-value less than 0.05 was considered statistical significant.

\section{Results}

Relevant baseline clinical characteristics of the patients are shown in Table 1. The details on uveitis manifestations at baseline are included in Table 2. Mean age was $51 \pm$ 15 years, nine patients were male. Before adalimumab was initiated all patients were treated with oral corticosteroids (starting dose 20-60 mg daily), if this did not have a positive effect, MTX was added (12.5-15 mg once a week orally). In eight cases, no MTX was added due to earlier reported side-effects. One patient (number 16 in Table 2) was previously treated with infliximab, however, she developed antibodies after 2 years of treatment. To reduce side-effects of treatment, adjunctive therapy in the studied population $(n=26)$ was tapered during treatment with adalimumab: prednisone from $15.6 \pm 10.7$ to $3.6 \pm 5.0$ $(p<0.01)$ and MTX from $9.6 \pm 5.5$ to $5.6 \pm 4.1(p<0.05)$, respectively. The dosages of these drugs could be tapered gradually within the first 6 months of treatment with adalimumab. Thereafter, all patients remained on the same (lower) dosage. After tapering, adjunctive therapy consisted of only oral corticosteroids in four patients $(5-10 \mathrm{mg}$ daily); corticosteroids together with methotrexate (MTX) in six (mean dose MTX 8.6 \pm 4.4 ; range 5-15 mg daily), and MTX alone in 12 patients (mean dose $7.6 \pm 2.4$; range 5$12.5 \mathrm{mg}$ once a week orally). Four patients did not use adjunctive therapy.

Table 2 provides the details on the intraocular inflammatory signs after 6 months of treatment with adalimumab. The results after 12 months of treatment with adalimumab are not shown in Table 2 for viewing purposes, since in

Table 2 Ocular manifestations of uveitis at baseline and after 6 months of treatment with adalimumab

\begin{tabular}{|c|c|c|c|c|c|c|c|c|c|c|c|c|}
\hline Patient & $\begin{array}{l}\text { Sex } \\
\text { age }\end{array}$ & $\begin{array}{l}\text { Involved } \\
\text { Eye OD/OS }\end{array}$ & $\begin{array}{l}\text { PAP OD } \\
\text { start } / 6 \mathrm{~m}\end{array}$ & $\begin{array}{l}\text { PAP OS } \\
\text { start/6 m }\end{array}$ & $\begin{array}{l}\text { MAC OD } \\
\text { start/6 m }\end{array}$ & $\begin{array}{l}\text { MAC OS } \\
\text { start } / 6 \mathrm{~m}\end{array}$ & $\begin{array}{l}\text { CHO OD } \\
\text { start } / 6 \mathrm{~m}\end{array}$ & $\begin{array}{l}\text { CHO OS } \\
\text { start } / 6 \mathrm{~m}\end{array}$ & $\begin{array}{l}\text { VAS OD } \\
\text { start } / 6 \mathrm{~m}\end{array}$ & $\begin{array}{l}\text { VAS OS } \\
\text { start } / 6 \mathrm{~m}\end{array}$ & $\begin{array}{l}\text { VIT OD } \\
\text { start } / 6 \mathrm{~m}\end{array}$ & $\begin{array}{l}\text { VIT OS } \\
\text { start } / 6 \mathrm{~m}\end{array}$ \\
\hline 1 & F 44 & $0 / 1$ & & $1 / 0$ & & $1 / 0$ & & & & & & \\
\hline 2 & F 34 & $0 / 1$ & & & & & & 1/1- & & & & \\
\hline 3 & M 56 & $1 / 1$ & & & & & $1 / 0$ & $1 / 0$ & & & & \\
\hline 4 & F 73 & $1 / 1$ & $1 / 0$ & $1 / 0$ & & & & & & & & \\
\hline 5 & F 64 & $1 / 1$ & & & & & $1 / 0$ & $1 / 0$ & & & $1 / 0$ & $1 / 0$ \\
\hline 6 & F 40 & $1 / 1$ & & & $1 / 0$ & $1 / 0$ & & & & & & \\
\hline 7 & F 58 & $1 / 1$ & & & $1 / 0$ & $1 / 1-$ & & & & & & \\
\hline 8 & F 79 & $1 / 1$ & $1 / 0$ & $1 / 0$ & & & $1 / 0$ & $1 / 0$ & & & & \\
\hline 9 & F 47 & $1 / 1$ & & & & & $1 / 1-$ & $1 / 1-$ & & & $1 / 0$ & $1 / 0$ \\
\hline 10 & F 35 & $1 / 0$ & & & $1 / 0$ & & $1 / 0$ & & & & & \\
\hline 11 & F 41 & $1 / 1$ & $1 / 0$ & $1 / 0$ & & & & & $1 / 0$ & $1 / 0$ & & \\
\hline 12 & M 69 & $1 / 1$ & & & $1 / 1-$ & $1 / 1-$ & & & & & & \\
\hline 13 & F 59 & $1 / 1$ & & & & & $1 / 0$ & $1 / 0$ & & & & \\
\hline 14 & M 67 & $1 / 1$ & & & & & & & & & $1 / 0$ & $1 / 0$ \\
\hline 15 & M 33 & $1 / 1$ & $1 / 1-$ & $1 / 1-$ & & & $1 / 1-$ & $1 / 1-$ & & & & \\
\hline 16 & F 56 & $0 / 1$ & & & & $1 / 0$ & & & & & & \\
\hline 17 & F 79 & $0 / 1$ & & & & $1 / 1-$ & & $1 / 1-$ & & & & \\
\hline 18 & M 46 & $1 / 1$ & & & & & $1 / 0$ & $1 / 0$ & & & $1 / 0$ & $1 / 0$ \\
\hline 19 & F 39 & $0 / 1$ & & $1 / 0$ & & & & & & & & \\
\hline 20 & M 43 & $1 / 1$ & & & & & $1 / 0$ & $1 / 0$ & & & & \\
\hline 21 & F 37 & $1 / 0$ & & & & & $1 / 0$ & & & & & \\
\hline 22 & F 23 & $1 / 1$ & $1 / 0$ & $1 / 0$ & & & $1 / 0$ & $1 / 0$ & & & & \\
\hline 23 & F 49 & $0 / 1$ & & $1 / 0$ & & & & & & & & \\
\hline 24 & M 64 & $1 / 1$ & & & $1 / 0$ & $1 / 0$ & $1 / 1-$ & $1 / 1-$ & & & & \\
\hline 25 & M 63 & $1 / 0$ & & & & & $1 / 0$ & & & & & \\
\hline 26 & M 41 & $1 / 0$ & & & & & & & & & $1 / 0$ & \\
\hline
\end{tabular}

$F$ female; $M$ male; $O D$ right eye; $O S$ left eye; $m$ months; $N L P$ no light perception; $P A P$ papillitis; $M A C$ macular edema; $C H O$ choroidal involvement; VAS vasculitis; VIT corpus vitreous cells; 1 present or yes; 0 absent or no; - partial improvement 
none of the patients the results regarding intraocular inflammatory signs changed between 6 and 12 months. Papillitis (the presence of inflammatory disc swelling) was present in eight patients and resolved in seven patients (no staining on FA), one had partial response (less staining on FA). Eight patients had macular involvement, this resolved in five of them (no leakage on FA or OCT) and a partial response was seen in three patients (less leakage). An example of resolved macular edema after treatment is shown in Fig. 1. Choroidal involvement was present in 15 patients and resolved in ten (clearance of inflammatory activity on funduscopy) whereas five had a partial response. Vasculitis resolved in the one patient (no leakage on FA as shown in Fig. 2). All of the five patients with vitreous involvement showed a clearing of the vitreous of at least two steps on fundus examination. The final outcome regarding intraocular inflammatory signs showed improvement in 22 patients $(85 \%)$ and stabilization in four patients $(15 \%)$.

Patient number 22 developed bilateral glaucoma prior to the start of adalimumab treatment, partly due to prednisone therapy, and was successfully treated with a glaucoma surgery procedure OD (Baerveldt implant) after eight months of adalimumab treatment. This procedure was performed successfully during adalimumab therapy and no activation was seen postoperatively.

Table 1 displays the effect on clinical manifestations after six and twelve months of treatment with adalimumab. Inflammatory parameters demonstrated a positive reaction during the anti-TNF- $\alpha$ treatment with adalimumab; the sIL$2 \mathrm{R}$ increased in three of 26 patients and decreased or stayed within normal limits in 23, whereas the ACE increased in
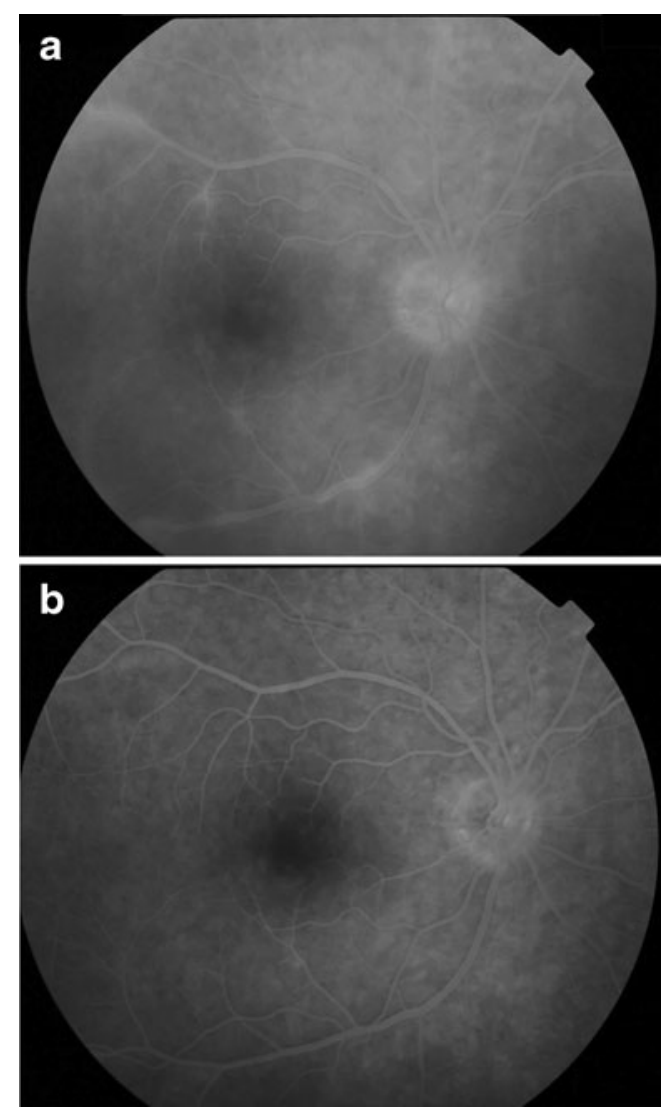

Fig. 2 Patient 11: Fluorescein angiography showing vasculitis before (top) and after (bottom) starting with adalimumab

two patients and decreased or stayed within normal limits in 24 of the 26. CRP levels at baseline were elevated in seven patients. Only one patient had as slightly elevated CRP
Fig. 1 Optical coherence tomography (top) and fluorescein angiography (bottom) of OS showing macula edema before (left) and after (right) starting with adalimumab
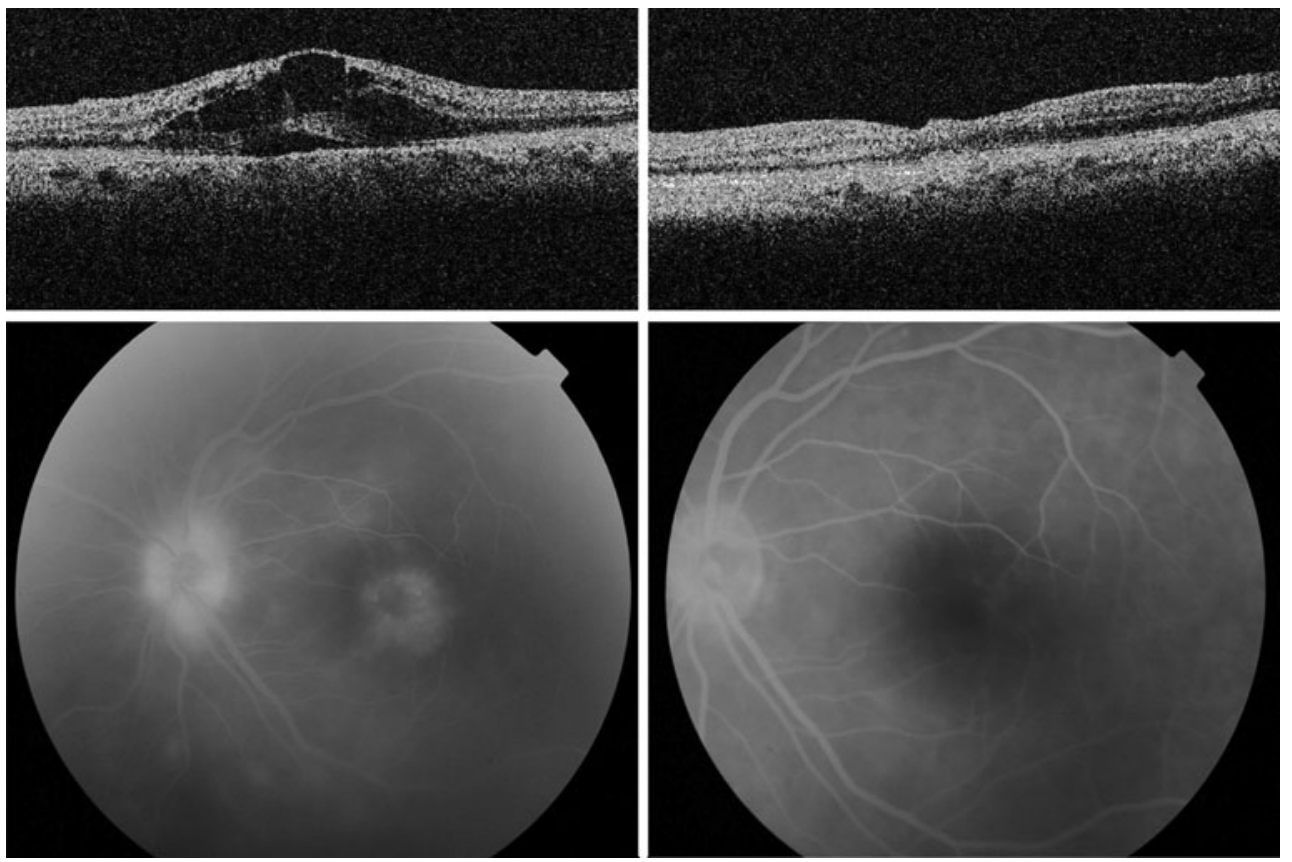
level after 6 months $(14 \mathrm{mg} / \mathrm{ml})$, whereas after 12 months in all patients the CRP level was within the normal range. Mean levels of CRP, ACE, and sIL-2R decreased significantly during treatment with adalimumab.

None of the patients had an abnormal FVC $(<80 \%$ of the predicted value); eight patients appeared to have a decreased diffusing capacity (DLCO $<80 \%$ of the predicted value) at baseline. After 6 months of treatment, seven of eight patients demonstrated an improvement of at least $10 \%$, whereas one patient remained stable. This increase in DLCO in patients with a decreased TLCO was significant $(p<0.01)$ and still present after 1 year of treatment.

Most of the patients $(n=21 ; 81 \%)$ suffered from fatigue (FAS score $\geq 22)$, whereas $11(42 \%)$ suffered from very severe fatigue (FAS score $>35$ ). Fourteen of these 21 patients (67\%) became less fatigued, four (19\%) remained stable, and three (14\%) reported a minor increase of their fatigue problems, as depicted by the FAS. The FAS score decreased significantly during treatment with adalimumab $(p<0.01$; Table 1).

Only one patient showed any signs of serious adverse effects during adalimumab treatment. This patient (number 16) developed a severe side effect at the injection site which led to the formation of a solid subcutaneous mass. However, because of the favorable effect on the uveitis she wanted to continue the treatment. Over time, this effect on the skin decreased but was still present after 12 months of treatment. Minor adverse effects, such as local skin reactions occurred in four patients. These minor adverse effects tapered off during the treatment period. All but one patient continued treatment with adalimumab during the follow-up period of 1 year. This one patient decided by herself to discontinue the adalimumab after a period of seven months into the treatment, although no side-effects had occurred.

\section{Discussion}

In this prospective case series of sarcoidosis patients with refractory chronic non-infectious posterior uveitis, adalimumab treatment appeared successful. For it not only showed an improvement of the intraocular inflammatory signs in the majority of patients (85\%), but also appeared to have a significantly positive effect on other sarcoidosis related features, including inflammatory parameters, diffusing capacity, and fatigue. Until the endpoint of the evaluation (December 2010), no deteriorations were reported in those successfully treated. Serious adverse effects only occurred in one patient.

The presence of posterior uveitis is a predictor of a poor visual prognosis, making treatment with immunosuppressive drugs mandatory $[6,8]$. All patients in our case series had uncontrolled inflammation due to prednisone and methotrexate resistance or intolerance, or a flare-up during treatment, and therefore ocular inflammation after 12 months of follow-up would have been expected to be worse without attempting a different therapy like with adalimumab. Intraocular inflammatory signs at baseline were modest in some of the included patients. However, in the past they had posterior uveitis which again showed a flare-up, also with respect to the serological inflammatory signs, despite treatment. Delay in effective treatment could lead to refractory inflammation, potentially leading to further damage in the eye. Given the fact that further therapeutic options were limited in these cases, early adjunctive treatment was indicated. Furthermore, six of the included patients responded to previous therapy with immunosuppressive drugs, but demonstrated severe adverse effects. Therefore, also in these patients, the intraocular inflammatory signs were not pronounced.

If visually disabling cataract formation or glaucoma develops in patients with uveitis, it is essential that no ocular inflammatory activity is present at the time of surgery [32]. One of our patients was successfully treated with a glaucoma surgery procedure (Baerveldt implant) during adalimumab therapy and no activation was seen postoperatively.

Disabling side-effects of steroid treatment, including cataract formation, glaucoma, osteoporosis, Cushing's syndrome or diabetes mellitus, and the refractory character of the uveitis in some sarcoidosis patients, stress the need for alternatives. In the patients of this case series, adalimumab appeared to be a well-tolerated alternative and the dosage of both prednisone and MTX could be tapered down significantly during this treatment.

Previously, adalimumab also appeared to be an appropriate alternative for infliximab in patients with Crohn's disease who first responded quite well, but had to stop due to antibody formation and/or the development of an allergic reaction and became intolerant to infliximab [33]. The decision to switch to another TNF- $\alpha$ inhibitor has not been studied systematically in sarcoidosis. However, switching from infliximab to adalimumab has been successful for some patients in case of allergic reactions [34]. In our institute, we successfully switched therapy in five patients (including patient 16 of the present study) whom had formed antibodies against infliximab (data not shown).

Previously, the combination of anti-TNF- $\alpha$ therapy and a cytotoxic drug has been shown to be superior to anti-TNF- $\alpha$ therapy alone [35]. However, this was not reported in all situations $[36,37]$. In our patients, the immunosuppressive medication as taken at the start of anti-TNF- $\alpha$ therapy was continued unless side effects occurred or contra-indications existed. In those cases the dosage of the MTX and prednisone was tapered off as described in the results section. 
It remains unclear how long anti-TNF- $\alpha$ therapy in a responding patient should be continued. In sarcoidosis, longer follow-up data are needed to determine the optimal treatment period to avoid disease relapse or deterioration. In our experience, treatment should be continued for at least a year instead of a shorter period as in rheumatoid arthritis.

A recent randomized controlled trial with infliximab versus placebo in chronic pulmonary sarcoidosis patients showed a change in FVC, the primary end point of that study [12]. Although in our studied population none of the patients had a decreased FVC $(<80 \%$ of predicted), eight showed a decreased diffusing capacity ( $<80 \%$ of predicted) at baseline. These latter patients demonstrated a significant improvement of the DLCO after 6 months and 1 year of treatment with adalimumab. Unfortunately, the DLCO was not evaluated in the previously mentioned infliximab study [12].

Several reports suggest that CRP can predict response to anti-TNF- $\alpha$ therapy in different inflammatory diseases [3842]. In line with this, in the present study, a decrease of the CRP was demonstrated after 6 months as well as after 1 year of treatment with adalimumab. Also, the decrease in $\mathrm{ACE}$ and sIL2-R and the improvement of fatigue during treatment with adalimumab is in accordance with findings of previous studies with anti-TNF- $\alpha$ agents, mainly infliximab, in sarcoidosis patients [11, 43]. Thus, although the primary reason for initiating treatment with adalimumab was refractory uveitis, the treatment also resulted in the improvement of systemic (inflammatory) manifestations of sarcoidosis.

This study has several limitations. Since during the follow-up period every sarcoidosis patient with refractory chronic non-infectious uveitis (as defined previously) in our clinic was treated with adalimumab in the absence of contra-indications, no control group could be evaluated. Also, the clinical examiner was not masked in grading response to treatment.

In conclusion, in this case series of sarcoidosis patients with refractory chronic non-infectious posterior uveitis, adalimumab appeared to be successful by showing improvement of intraocular inflammatory signs. Moreover, other relevant clinical indicators of disease activity improved as well. Future randomized studies are needed to determine optimal dosage, dose interval, and duration of therapy in refractory multisystemic sarcoidosis.

\section{Acknowledgments}

Funding/support None.

\section{Financial disclosure None.}

Contributions to authors Design of the study (RE, RM, MD, JS), conduct of the study (RE, RM, PW, MD), analysis and interpretation of the data (RE, RM, PW, JS, MD), preparation (RE, RM, PW, JS, MD).
Statement about Conformity with author information Adherence to the Declaration of Helsinki and all federal laws in the Netherlands.

Conflict of interest No conflicting relationship exists for any author. The authors have full control of all primary data and allow Graefes Archive for Clinical and Experimental Ophthalmology to review our data upon request.

Open Access This article is distributed under the terms of the Creative Commons Attribution Noncommercial License which permits any noncommercial use, distribution, and reproduction in any medium, provided the original author(s) and source are credited.

\section{References}

1. Rothova A (2000) Ocular involvement in sarcoidosis. Br J Ophthalmol 84:110-116

2. Kosmorsky GS, Meisler DM, Rice TW, Meziane MA, Lowder CY (1998) Chest computed tomography and mediastinoscopy in the diagnosis of sarcoidosis-associated uveitis. Am J Ophthalmol 126:132-134

3. Iannuzzi MC, Rybicki BA, Teirstein AS (2007) Sarcoidosis. N Engl J Med 357:2153-2165

4. Herbort CP, Rao NA, Mochizuki M (2009) International criteria for the diagnosis of ocular sarcoidosis: results of the first International Workshop On Ocular Sarcoidosis (IWOS). Ocul Immunol Inflamm 17:160-169

5. Martin TM, Doyle TM, Smith JR, Dinulescu D, Rust K, Rosenbaum JT (2003) Uveitis in patients with sarcoidosis is not associated with mutations in NOD2 (CARD15). Am J Ophthalmol 136:933-935

6. Dana MR, Merayo-Lloves J, Schaumberg DA, Foster CS (1996) Prognosticators for visual outcome in sarcoid uveitis. Ophthalmology 103:1846-1853

7. Ardoin SP, Kredich D, Rabinovich E, Schanberg LE, Jaffe GJ (2007) Infliximab to treat chronic noninfectious uveitis in children: retrospective case series with long-term follow-up. Am J Ophthalmol 144:844-849

8. Dev S, McCallum RM, Jaffe GJ (1999) Methotrexate treatment for sarcoid-associated panuveitis. Ophthalmology 106:111-118

9. Baughman RP, Lower EE, Drent M (2008) Inhibitors of tumor necrosis factor (TNF) in sarcoidosis: who, what, and how to use them. Sarcoidosis Vasc Diffuse Lung Dis 25:76-89

10. Baughman RP, Costabel U, du Bois RM (2008) Treatment of sarcoidosis. Clin Chest Med 29:533-548, ix-x

11. Elfferich MD, Nelemans PJ, Ponds RW, Vries JD, Wijnen PA, Drent M (2010) Everyday Cognitive Failure in Sarcoidosis: the Prevalence and the Effect of Anti-TNF- $\alpha$ - treatment. Respiration

12. Baughman RP, Drent M, Kavuru M, Judson MA, Costabel U, du Bois R, Albera C, Brutsche M, Davis G, Donohue JF, Muller-Quernheim J, Schlenker-Herceg R, Flavin S, Lo KH, Oemar B, Barnathan ES (2006) Infliximab therapy in patients with chronic sarcoidosis and pulmonary involvement. Am J Respir Crit Care Med 174:795-802

13. Baughman RP, Lower EE (2001) Infliximab for refractory sarcoidosis. Sarcoidosis Vasc Diffuse Lung Dis 18:70-74

14. Galor A, Perez VL, Hammel JP, Lowder CY (2006) Differential effectiveness of etanercept and infliximab in the treatment of ocular inflammation. Ophthalmology 113:2317-2323

15. Hale S, Lightman S (2006) Anti-TNF therapies in the management of acute and chronic uveitis. Cytokine 33:231-237

16. Sobrin L, Kim EC, Christen W, Papadaki T, Letko E, Foster CS (2007) Infliximab therapy for the treatment of refractory ocular inflammatory disease. Arch Ophthalmol 125:895-900 
17. Petropoulos IK, Vaudaux JD, Guex-Crosier Y (2008) Anti-TNFalpha therapy in patients with chronic non-infectious uveitis: the experience of Jules Gonin Eye Hospital. Klin Monbl Augenheilkd 225:457-461

18. Lindstedt EW, Baarsma GS, Kuijpers RW, van Hagen PM (2005) Anti-TNF-alpha therapy for sight threatening uveitis. $\mathrm{Br} \mathrm{J}$ Ophthalmol 89:533-536

19. Takase K, Ohno S, Ideguchi H, Uchio E, Takeno M, Ishigatsubo Y (2011) Successful switching to adalimumab in an infliximaballergic patient with severe Behçet disease-related uveitis. Rheumatol Int 31:243-245

20. Seiderer J, Brand S, Dambacher J, Pfennig S, Jurgens M, Goke B, Ochsenkuhn $T$ (2007) Adalimumab in patients with Crohn's disease-safety and efficacy in an open-label single centre study. Aliment Pharmacol Ther 25:787-796

21. Simonini G, Taddio A, Cattalini M, Caputo R, De Libero C, Naviglio S, Bresci C, Lorusso M, Lepore L, Cimaz R (2010) Prevention of flare recurrences in childhood refractory chronic uveitis: an open-label comparative study of Adalimumab versus Infliximab. Arthritis Care Res (Hoboken)

22. Kamphuis L WL-T, Dik W, et al. (2011) Efficacy of adalimumab in chronically active and symptomatic sarcoidosis patients. American Journal of Respiratory and Critical Care Medicine (in press)

23. Callejas-Rubio JL, Ortego-Centeno N, Lopez-Perez L, Benticuaga MN (2006) Treatment of therapy-resistant sarcoidosis with adalimumab. Clin Rheumatol 25:596-597

24. Field S, Regan AO, Sheahan K, Collins P (2010) Recalcitrant cutaneous sarcoidosis responding to adalimumab but not to etanercept. Clin Exp Dermatol 35:795-796

25. Philips MA, Lynch J, Azmi FH (2005) Ulcerative cutaneous sarcoidosis responding to adalimumab. J Am Acad Dermatol 53:917

26. Heffernan MP, Smith DI (2006) Adalimumab for treatment of cutaneous sarcoidosis. Arch Dermatol 142:17-19

27. Hunninghake GW, Costabel U, Ando M, Baughman R, Cordier JF, du Bois R, Eklund A, Kitaichi M, Lynch J, Rizzato G, Rose C, Selroos O, Semenzato G, Sharma OP (1999) ATS/ERS/WASOG statement on sarcoidosis. American Thoracic Society/European Respiratory Society/World Association of Sarcoidosis and other Granulomatous Disorders. Sarcoidosis Vasc Diffuse Lung Dis 16:149-173

28. Bartalesi F, Vicidomini S, Goletti D, Fiorelli C, Fiori G, Melchiorre D, Tortoli E, Mantella A, Benucci M, Girardi E, Cerinic MM, Bartoloni A (2009) QuantiFERON-TB Gold and the TST are both useful for latent tuberculosis infection screening in autoimmune diseases. Eur Respir J 33:586-593

29. Jabs DA, Nussenblatt RB, Rosenbaum JT (2005) Standardization of uveitis nomenclature for reporting clinical data. Results of the First International Workshop. Am J Ophthalmol 140:509-516

30. Mostard RL, Voo S, van Kroonenburgh MJ, Verschakelen JA, Wijnen PA, Nelemans PJ, Erckens RJ, Drent M (2011) Inflammatory activity assessment by F18 FDG-PET/CT in persistent symptomatic sarcoidosis. Respir Med 2011 Sep 5 [Epub ahead of print]

31. de Kleijn WP, Elfferich MD, De Vries J, Jonker GJ, Lower EE, Baughman RP, King TE Jr, Drent M (2009) Fatigue in sarcoidosis: American versus Dutch patients. Sarcoidosis Vasc Diffuse Lung Dis 26:92-97

32. Akova YA, Foster CS (1994) Cataract surgery in patients with sarcoidosis-associated uveitis. Ophthalmology 101:473-479

33. Sandborn WJ, Hanauer S, Loftus EV Jr, Tremaine WJ, Kane S, Cohen R, Hanson K, Johnson T, Schmitt D, Jeche R (2004) An open-label study of the human anti-TNF monoclonal antibody adalimumab in subjects with prior loss of response or intolerance to infliximab for Crohn's disease. Am J Gastroenterol 99:1984 1989

34. Baughman RP (2007) Tumor necrosis factor inhibition in treating sarcoidosis: the American experience. Revista Portuguesa de Pneumonologia 13:S47-S50

35. Breedveld FC, Weisman MH, Kavanaugh AF, Cohen SB, Pavelka K, van Vollenhoven R, Sharp J, Perez JL, Spencer-Green GT (2006) The PREMIER study: A multicenter, randomized, doubleblind clinical trial of combination therapy with adalimumab plus methotrexate versus methotrexate alone or adalimumab alone in patients with early, aggressive rheumatoid arthritis who had not had previous methotrexate treatment. Arthritis Rheum 54:26-37

36. Breban M, Ravaud P, Claudepierre P, Baron G, Henry YD, Hudry C, Euller-Ziegler L, Pham T, Solau-Gervais E, Chary-Valckenaere I, Marcelli C, Perdriger A, Le Loet X, Wendling D, Fautrel B, Fournie B, Combe B, Gaudin P, Jousse S, Mariette X, Baleydier A, Trape G, Dougados M (2008) Maintenance of infliximab treatment in ankylosing spondylitis: results of a one-year randomized controlled trial comparing systematic versus ondemand treatment. Arthritis Rheum 58:88-97

37. van Riel PL, Taggart AJ, Sany J, Gaubitz M, Nab HW, Pedersen R, Freundlich B, MacPeek D (2006) Efficacy and safety of combination etanercept and methotrexate versus etanercept alone in patients with rheumatoid arthritis with an inadequate response to methotrexate: the ADORE study. Ann Rheum Dis 65:1478-1483

38. Wolbink GJ, Voskuyl AE, Lems WF, de Groot E, Nurmohamed MT, Tak PP, Dijkmans BA, Aarden L (2005) Relationship between serum trough infliximab levels, pretreatment $\mathrm{C}$ reactive protein levels, and clinical response to infliximab treatment in patients with rheumatoid arthritis. Ann Rheum Dis 64:704-707

39. Gratacos J, Casado E, Real J, Torre-Alonso JC (2007) Prediction of major clinical response (ACR50) to infliximab in psoriatic arthritis refractory to methotrexate. Ann Rheum Dis 66:493-497

40. Stone MA, Payne U, Pacheco-Tena C, Inman RD (2004) Cytokine correlates of clinical response patterns to infliximab treatment of ankylosing spondylitis. Ann Rheum Dis 63:84-87

41. Louis E, Vermeire S, Rutgeerts P, De Vos M, Van Gossum A, Pescatore P, Fiasse R, Pelckmans P, Reynaert H, D'Haens G, Malaise M, Belaiche J (2002) A positive response to infliximab in Crohn disease: association with a higher systemic inflammation before treatment but not with -308 TNF gene polymorphism. Scand J Gastroenterol 37:818-824

42. Sweiss NJ, Barnathan ES, Lo K, Judson MA, Baughman R (2010) $\mathrm{C}$-reactive protein predicts response to infliximab in patients with chronic sarcoidosis. Sarcoidosis Vasc Diffuse Lung Dis 27:49-56

43. Keijsers RG, Verzijlbergen JF, van Diepen DM, van den Bosch JM, Grutters JC (2008) 18 F-FDG PET in sarcoidosis: an observational study in 12 patients treated with infliximab. Sarcoidosis Vasc Diffuse Lung Dis 25:143-149 